\title{
Sry-related High Mobility Group Box 17 Functions as a Tumor Suppressor by Antagonizing the Wingless-related Integration Site Pathway
}

\author{
Maha Anani', Ikuo Nobuhisa ${ }^{2, *}$, Tetsuya Taga ${ }^{2, *}$ \\ ${ }^{1}$ Department of Clinical Pathology, Faculty of Medicine, Suez Canal University, Ismailia, Egypt, ${ }^{2}$ Department of Stem Cell \\ Regulation, Medical Research Institute, Tokyo Medical and Dental University (TMDU), Tokyo, Japan
}

\begin{abstract}
A transcription factor Sry-related high mobility group box (Sox) 17 is involved in developmental processes including spermatogenesis, cardiovascular system, endoderm formation, and so on. In this article, we firstly review the studies on the relation between the Sox17 expression and tumor malignancy. Although Sox17 positively promotes various tissue development, most of the cancers associated with Sox17 show decreased expression levels of Sox17, and an inverse correlation between Sox17 expression and malignancy is revealed. We briefly discuss the mechanism of such Sox17 down-regulation by focusing on DNA methylation of CpG sites located in the Sox17 gene promoter. Next, we overview the function of Sox17 in the fetal hematopoiesis, particularly in the dorsal aorta in midgestation mouse embryos. The Sox17 expression in hematopoietic stem cell (HSC)-containing intra-aortic hematopoietic cell cluster (IAHCs) is important for the cluster formation with the hematopoietic ability. The sustained expression of Sox17 in adult bone marrow HSCs and the cells in IAHCs of the dorsal aorta indicate abnormalities that are low lymphocyte chimerism and the aberrant proliferation of common myeloid progenitors in transplantation experiments. We then summarize the perspectives of Sox17 research in cancer control.
\end{abstract}

Key Words Transcription factors, Neoplasms, Methylation, Hematopoiesis, Aotra

\section{INTRODUCTION}

A transcription factor Sox17 is a member of Sry-related high mobility group (HMG) box (Sox) family proteins that is composed of 20 proteins in mouse and human [1]. Sox proteins contain the HMG box that interacts with DNA containing the consensus sequences, $(A / T)(A / T) C A A(A / T) G$ [1]. By grouping Sox proteins based on their similarities of their amino acid sequences in the HMG-box, Sox17 belongs to a subfamily $F$ that is composed of Sox7, Sox17, and Sox18 [2]. The Sox17 protein contains the transcription activation domain which includes the region binding to the $\beta$-catenin, a component of the Wingless-related integration site (Wnt) signaling pathway [3]. Sox17 is known to be a marker of endodermal cells and expressed in endodermal and mesodermal cell lineages in the fetal stage $[4,5]$. Sox17 is firstly identified as an activator in mouse spermatogenesis [6] and has a function in the development of heart from the endocardium differentiation [7]. Sox17 heterozygous mutant female mice display a failure of embryo implantation [8]. Moreover, Sox17 heterozygous mutant embryos cause embryonic cholecystitis [9], defective gallbladder contraction [9], and gallbladder wall abnormality [10] in perinatal biliary atresia [11]. In the wild-type mice, a transient increase in the Sox17 expression in oligodendrocyte progenitors is required for the oligodendrocyte differentiation $[12,13]$. The importance of Sox17 is reported in the fetal and neonatal hematopoiesis [14,15].

Recently, the relationship between malignancies in cancers and the expression of Sox17 which is altered by methylation in the CpG sequences in the Sox17 promoter is reported (reviewed in [16]). The focus of this review is to highlight the function of Sox17 and its role in cancer and fetal hematopoiesis.

Received November 21, 2020, Revised December 1, 2020, Accepted December 5, 2020

Correspondence to Ikuo Nobuhisa, E-mail: nobuhisa.scr@mri.tmd.ac.jp, https://orcid.org/0000-0002-3335-7714

Check for updates

Tetsuya Taga, E-mail: taga.scr@mri.tmd.ac.jp, https://orcid.org/0000-0002-1625-0122

*These authors contributed equally to this work as co-correspondence authors.

(i) (s) This is an Open Access article distributed under the terms of the Creative Commons Attribution Non-Commercial License, which permits unrestricted noncommercial use, distribution, and reproduction in any medium, provided the original work is properly cited.

Copyright (C) 2020 Korean Society of Cancer Prevention 


\section{RELATIONSHIP BETWEEN CANCER AND THE SOX17 EXPRESSION}

The expression levels of Sox17 mRNA and protein are examined in various cancer patients (Table 1). Although Sox17 positively promotes various tissue development, the Sox17 expression is upregulated in a few cancer tissues. A high expression level of Sox17 is observed in a seminoma cell line [17] and knockdown of Sox17 in a seminoma-like cell line leads to a loss of its pluripotency [18]. Sox17 is expressed in endothelial cells along with Sox7 and Sox18 of the developing vasculature, and has redundant functions with Sox18 in postnatal angiogenesis and early cardiovascular development $[19,20]$. In tumor vessels of mice implanted with the Lewis lung carcinoma and melanoma, the Sox17 expression level is higher compared to controls [21]. Moreover, endothelial cell-specific Sox17 deletion in mice transplanted with lung carcinoma cells led to the reduced tumor angiogenesis and vascular abnormalities, whereas the endothelial cell-specific overexpression of Sox17 using a doxycycline-inducible gainof-function mice induces tumor progression and angiogenesis [21].

Conversely, various malignancies exhibit a decrease in the expression level of Sox17. These include human hepatocellular carcinoma [22], breast cancer [23], cholangiocarcinoma [24], colorectal cancer [25], gastric cancer [26], ESCC [27], and endometrial cancer [28] (Table 1) [29-35]. Moreover, a decrease of the Sox17 expression in various cancer tissues is closely related to their malignancies and the time of relapse-free survival. For example, the Sox17 expression level is inversely correlated with the tumor grade in the breast cancer patients [36] and a reduction of the Sox17 expression level in primary and metastatic melanomas shows the correlation with disease progression [37].

Increased DNA methylation at CpG sites in gene promoters is generally considered to be important for gene silencing. The Sox17 promoter methylation status is analyzed in tumor tissues, revealing the reduction of Sox17 expression. A significant increase in the DNA methylation of the Sox17 promoter was observed in those cells derived from liver [22], breast $[23,31,34]$, bile duct [24], colon [25], lung [29], thyroid grand [30], cervix [33], adenoma [35], and esophagus [38]. Moreover, the promoter methylation status of the Sox17 gene in various cancers including those of colon [25], breast [31,34], stomach [32], and esophagus [38], is closely related to their malignancies [3]. For instance, in the primary esophageal cancer, the proportion of the methylation in the Sox17 gene promoter is highly correlated with the grade of dysplasia/cancer [38]. These results are in reasonable agreement with the observation of the negative correlation between Sox17 expression levels and malignancy. Furthermore, analysis of the cell-free DNA in plasma from breast and lung cancer patients $[36,39]$ detects the increase of the promoter methylation at the Sox17 gene. These data open the possibility for implementing the breast and lung cancer screening at an early stage.

The molecular mechanism underlying inverse correlation between Sox17 expression and malignant progression is attributable to an inhibition of the Wnt signal pathway by Sox17 (Fig. 1). The Wnt signaling is known to be important

Table 1. Sox17 expression in various cancer cells

\begin{tabular}{|c|c|c|c|c|c|}
\hline Sox17 expression & Methylation & Malignant tissue & Effector modules & Affected pathway/outcome & Reference \\
\hline Up & ND & Seminiferous epithelium & Oct4/Sox2 & Oct4/Pluripotency & 17,18 \\
\hline Up & ND & Tumor endothelial cells & VEGFR2 & VEGF/proliferation & 21 \\
\hline Down & Promoter & Adenoma & ND & ND & 35 \\
\hline Down & Promoter & Bile duct & ND & Wnt/proliferation & 24 \\
\hline Down & Promoter & Breast & $\beta$-catenin & Wnt/proliferation & $24,31,34,36$ \\
\hline Down & Promoter & Breast & miR-194-5p & Sox17 expression & 51 \\
\hline Down & Promoter & Colon & miR-371-5p & Sox $2 /$ proliferation metastasis & 25,52 \\
\hline Down & Promoter & Esophagus & $\beta$-catenin, miR-141 & Wnt/proliferation & 38 \\
\hline Down & Promoter & Esophagus & DNA repair genes & Activation of DNA repair & 49 \\
\hline Down & Promoter & Hematopoietic cells & ND & ND & 70,71 \\
\hline Down & Promoter & Hepatocyte & $\beta$-catenin & Wnt/proliferation & 22 \\
\hline Down & Promoter & Lung & $\beta$-catenin & Wnt/proliferation & 29,39 \\
\hline Down & Promoter & Stomach & ND & ND & 32 \\
\hline Down & Promoter & Thyroid grand & $\beta$-catenin & Wnt/proliferation & 30 \\
\hline Down & Likely promoter & Cervical region & ND & ND & 33 \\
\hline Down & ND & Esophagus & ND & ND & 27 \\
\hline Down & ND & Pigment cell & ND & ND & 37 \\
\hline Down & ND & Stomach & ND & ND & 26 \\
\hline Down & ND & Uterus & $\operatorname{miR}-21-5 p$ & $\begin{array}{l}\text { Epithelial to mesenchymal } \\
\text { transition }\end{array}$ & 50 \\
\hline Down & ND & Uterus & ND & ND & 28 \\
\hline
\end{tabular}

Sox, Sry-related high mobility group box; ND, no data; Wnt, Wingless-related integration site. 
for the differentiation and the proliferation of stem cells and tumor development [40]. The Wnt protein initially binds to such receptors as Frizzled and the lipoprotein receptor-related protein-5/6. A Wnt downstream effector protein, a serine/ threonine kinase glycogen synthetase $3 \beta$ (GSK3 $\beta$ ), is active when Wnt is not present and directly phosphorylates $\beta$-catenin protein. The phosphorylated $\beta$-catenin is then degraded by the ubiquitin-proteasome system. Following Wnt stimulation, a reduction of the GSK3 $\beta$ kinase activity induces the accumulation of unphosphorylated $\beta$-catenin protein and leads to the translocation of unphosphorylated $\beta$-catenin to the nucleus. The nuclear $\beta$-catenin bound to T-cell factor/lymphoid enhancer factor (TCF/LEF) transcription factors activates the target gene expression. This Wnt pathway is referred to as the canonical pathway. Sox17 has the region binding to $\beta$-catenin in the transactivation domain, which is conserved among species [41]. In the muscle satellite cells, SoxF competitively inhibits the $\beta$-catenin-mediated activation of the TCF/LEF promoter [42]. Enforced expression of Sox17 in cancer cells represses $\beta$-catenin and TCF activity on the promoter [43] and thereby reduced the Wnt signaling-dependent proliferation of cholangiocarcinoma cells [44]. Treatment of cholangiocarcinoma cells with 5-aza-2'deoxycytidine, which inhibits the DNA methyltransferase and reduces the methylation in CpG sites, increases the expression of inhibitory proteins containing Sox17 for the Wnt signaling pathway [24]. In cervical cancer cells, Sox17 directly binds to the $\beta$-catenin gene promoter and reduces the $\beta$-catenin expression followed by the inhibition of the Wnt signaling [45]. These results indicate that Sox17 acts as a tumor suppressor in these cancer cells. In the endometrioid endometrial carcinoma, frameshift mutations in gene encoding Sox 17 , which cause the deletion of the transactivation domain containing the $\beta$-catenin binding motif, results in the loss of Sox17 transcriptional activity [46].
There have been several reports describing signal pathways and molecules in cancers associated with the Sox17 expression. In seminoma with low expression of Sox17, Akt-, Erk-, EphA3-, and Tie2/TEK-signaling pathways are up-regulated [47]. Pancreatic cancer model mice expressing an activated form of Kras (KrasG12D) exhibit the reduced Sox17 expression [48]. In esophageal squamous cell carcinoma (ESCC) with decreased expression of Sox17, overexpression of fibronectin (FN1) and metastasis associated in colon cancer 1 (MACC1), whose expression levels are low in ESCC, abolishes Sox17-induced migration and invasion, suggesting that FN1 and MACC1 are downstream effector molecules of Sox17 [27].

Other mechanisms of cancer progression associated with the reduction of the Sox17 expression are also reported. Overexpression of Sox17 in radio-resistant ESCC line cells decreases the expression of DNA repair and DNA damage response genes and the reduction of tumor growth, suggesting that cancers with reduced Sox17 expression have increased expression of DNA repair and DNA damage response genes [49]. Moreover, functional relationships between microRNAs and Sox17 in cancer have been reported. Introduction of microRNA-141 in an esophageal cancer induces the reduction of Sox17 expression and the activation of the Wnt signaling pathway [38]. Overexpression of miR-21-5p in endometrial cancer cells promotes epithelial to mesenchymal transition with a decrease of Sox17 expression [50]. Knockdown of miR-194-5p, which is a target molecule of Sox17, in breast cancer inhibits the tumor growth together with an increased Sox17 expression [51]. In colorectal cancer, the expression of a microRNA, miR-371-5p, is upregulated by the Sox17-mediated activation of the miR-371-5p promoter. Shutdown of the Sox17 expression with the short hairpin RNA in colorectal cancer cells enhances the tumor growth and metastasis in a
A

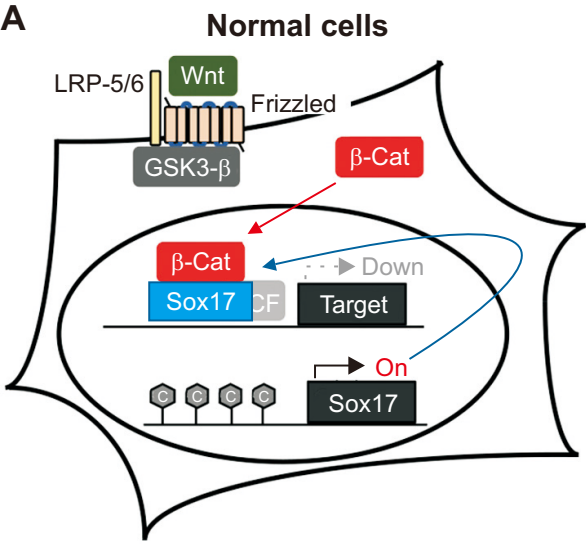

B

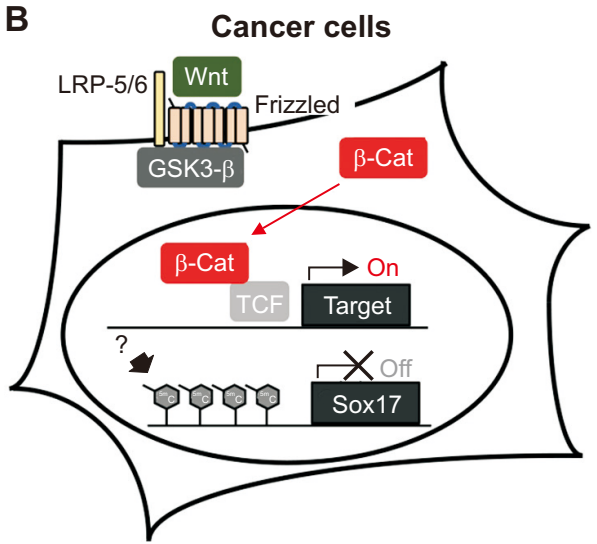

Figure 1. Mechanisms underlying the inverse correlation between Sox17 expression and malignancy. (A) In normal cells, Sox17 protein binds to $\beta$-Cat which is an essential factor in the Wnt signaling pathway, and in turn inhibits the transcription activity of the $\beta$-Cat/TCF complex which normally induces Wnt-dependent gene expression. (B) In various cancer cells, the expression of Sox17 is downregulated by methylation of its promoter, and the $\beta$-Cat/TCF complex induces expression of Wnt-dependent genes. Regulatory factors for increased methylation in the Sox 17 gene promoter are not identified. LRP, lipoprotein receptor-related protein; Wnt, Wingless-related integration site; GSK3- $\beta$, glycogen synthetase 3 $\beta$; $\beta$-Cat, $\beta$-catenin; Sox, Sry-related high mobility group box; TCF, T-cell factor. 
transplantation experiment, whereas introduction of the miR371-5p into the cancer cells to block Sox17 expression, leads to the reduction of tumor proliferation and metastasis [52].

\section{INVOLVEMENT OF SOX17 IN MIDGESTATIONAL HEMATOPOIESIS}

Hematopoietic stem/progenitor cells (HSPCs) are present in the aorta-gonad-mesonephros (AGM) region in midgestation embryos [53,54]. Hematopoietic cells emerge from the hemogenic endothelium, which is a common progenitor of the endothelial cells and hematopoietic cells, and form the intra-aortic hematopoietic cell clusters (IAHCs) $[55,56]$. The c-Kit protein, which is a marker of HSPCs in fetal liver and adult bone marrow, is expressed consistently in cells of IAHCs [56]. Markers of endothelial cells (vascular endothelial [VE]-cad and CD31) are found in cells located on the vessel wall side of IAHCs, while the hematopoietic cell marker, CD45, is expressed on cells on the vessel lumen side of IAHCs [56]. This suggests that hematopoietic cells that emerge from hemogenic endothelia are differentiated and matured in IAHCs. Sox17 is found to be expressed in cells located in the vessel wall side of IAHCs as assessed by in situ hybridization and whole-mount immunohistochemistry [5759]. Researchers have attempted to isolate cells from IAHCs, which contain HSPCs, and have performed the transplantation experiments. CD45 $5^{+} \mathrm{VE}-\mathrm{cad}^{+}$cells [60] and $\mathrm{CD} 31^{+} \mathrm{C}-\mathrm{Kit}^{+} \mathrm{S}-$ $\mathrm{SEA} 1^{+}$cells [56] in the AGM region of E11.5 embryos contain the long-term repopulating HSCs. Moreover, CD45 ${ }^{\text {low }} \mathrm{C}-\mathrm{Kit}^{\text {high }}$ cells have the highest hematopoietic capacity in AGM cells at midgestation [61]. When the Sox17 gene is overexpressed in CD45 ${ }^{\text {low }} \mathrm{C}-\mathrm{Kit}^{\text {high }}$ AGM cells of E10.5 embryos co-cultured with stromal cells in the presence of cytokines (the main cytokine is thrombopoietin [62]), the cluster formation of undifferentiated Sox17-expressing cells was found [58]. Blockage of the Sox17 expression in Sox17-trausduced cells resulted in a release of differentiated hematopoietic cells from cell clusters [58]. Lethally irradiated mice transplanted with Sox17-transduced cells by intra-bone marrow injection showed the longterm repopulating ability [58]. This suggests that Sox 17 plays a key role in differentiation and self-renewal of HSCs in IAHCs (Fig. 2A; also see the next section on leukemia-like abnormalities).

The molecular mechanism responsible for maintaining the formation of cell clusters and the hematopoietic activity by the introduction of the transcription factor Sox17 in cells of IAHCs have been suggested. Sox17 interacts with Notch1 promoter regions of endothelium [57] and induces the Notch1 expression [63]. The Notch1 signaling pathway is known to regulate cell proliferation, fate, differentiation, and death. Notch1, Notch4, and the Notch ligand, Delta-like ligand 4, is expressed in endothelial cells of dorsal aorta as well as IAHCs [64]. Sox17 directly induces the expression of the Notch1 gene and the Notch1-downstream molecule Hes1, and the Sox17-Notch1-Hes1 axis is important for the maintenance of the hematopoietic activity in Sox17-transduced cells

A

A $<$ Midgestation mouse embryos>

Dorsal aorta

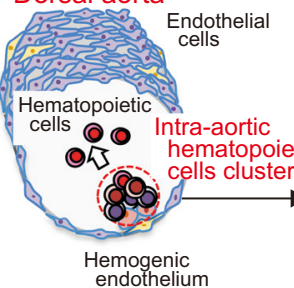

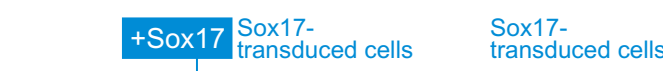

$\begin{array}{ll}\text { transduced cells } & \text { transduced cels } \\ \text { Formation of } & \text { Formation of }\end{array}$

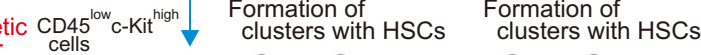
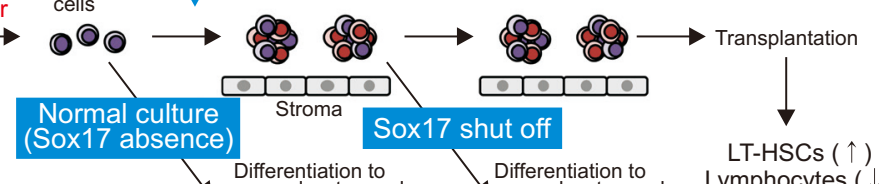

Differentiation to
granulocytes and granulocytes and oro odos?

Lymphocytes $(\downarrow)$ $\operatorname{CMP}(\uparrow)$

B <Adult>

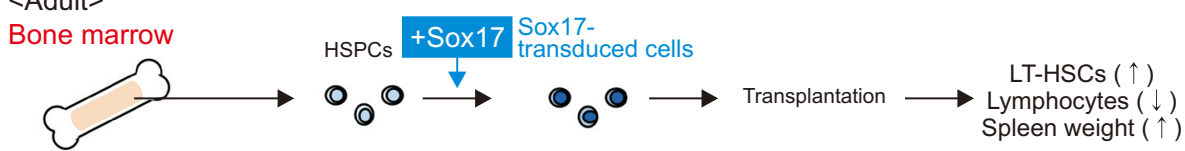

Figure 2. Effects of manipulated expression of Sox17 on the hematopoiesis in intra-aortic hematopoietic cell clusters in dorsal aorta at midgestation mouse embryos and adult bone marrow HSPCs. (A) Sox17-transduced intra-aortic hematopoietic cell clusters maintain the cluster formation with hematopoietic activity and shutdown of the Sox17 expression in Sox17-trausduced clusters results in the dissociation of the cluster and a release of differentiated hematopoietic cells. In transplantation experiments, Sox17-transduced intra-aortic hematopoietic cell clusters have the long-term reconstituting activity with low lymphocyte chimerism, and a greater increase of CMPs. (B) Sox17-transduced HSPCs in adult bone marrow also have the long-term reconstituting activity with low lymphocyte chimerism. Sox, Sry-related high mobility group box; HSPCs, hematopoietic stem/progenitor cells; LT-HSCs, long-term repopulating hematopoietic stem cells; CMP, common myeloid progenitors; HSPCs, hematopoietic stem/ progenitor cells. 
[59]. Furthermore, adherent molecules, such as endothelial cell-selective adhesion molecules (ESAM) and VE-cad directly induced by Sox17, are required for the formation of the cell cluster with the hematopoietic ability in Sox17-transduced cells [65].

The Sox17 expression is not found in adult bone marrow. Sox17 deletion in HSCs of neonate mice results in a significant decrease of the HSC number followed by death, whereas the loss of Sox17 in HSCs in adult mice has no effect on the HSC number [14]. Expression of the Sox17 gene was found to be decreased with development in several tissues such as fetal liver, newborn liver, and two week-old bone marrow [15]. The Sox17 expression depends on the status of hematopoietic maturation. Ectopic overexpression of Sox17 in HSCs in the bone marrow of adult mice increases the longterm reconstitution ability and induces the fetal-stage-specific hematopoietic marker expression [15].

The Wnt signaling pathway is important to maintain the stem cell capacity in adult bone marrow HSCs [66], whereas HSCs are observed in the mice lacking $\beta$-catenin and $\gamma$-catenin [67]. These discrepancy is explained by a requirement of the appropriate signal intensity of the Wnt pathway in the limited stage, but the specific stage has not been clarified [66]. In the fetal liver, Wnt3a-deficient mice reduced the number of HSCs and the reconstituted capacity in fetal liver [68]. In the AGM region in midgestation embryos, non-phosphorylated $\beta$-catenin is detected in the hemogenic endothelium of the dorsal aorta, and the treatment of the explant culture of the AGM region with the GSK3- $\beta$ inhibitor, which does not cause the degradation of $\beta$-catenin, leads to an increase in the longterm reconstituting activity of the cells by the transplantation [69]. In the future, it is necessary to investigate whether Sox17 directly modulates $\beta$-catenin and the Wnt signal pathway.

\section{LEUKEIMIA-LIKE ABNORMALITIES OF SOX17-SUSTAINED EXPRESSION IN HSPCS IN TRANSPLANTED MICE}

Leukemia includes various types of blood cancers. Methylation of CpG sites in the Sox17 gene is reported in patients of the acute myeloid leukemia (AML) [70]. A quantitative PCR analysis shows that the expression level of Sox17 in patients is decreased in AML patients as compared with controls [71].

Ectopic expression of Sox17 in adult bone marrow HSPCs resulted in low $\mathrm{B}$ - and T-lymphocyte chimerism in transplanted mice (Fig. 2B) and the secondary transplantation of whole bone marrow cells from primary recipients led to death which was accompanied by a decrease of lymphocytes [15]. Moreover, the splenic hypertrophy is observed in this transplantation experiment [15]. Sox17-transduced IAHCs similarly exhibited the poor lymphocyte differentiation capacity in transplanted mice (see the "transplantation" part of Fig. 2A) [58]. However, this study did not explain why B and T lympho- cytes derived from Sox17-transduced cells were infrequently distinguished in the cells of recipient mice.

Linage marker ${ }^{-}$Sca- $1^{-} \mathrm{c}$-Kit ${ }^{+}$cells in adult bone marrow are classified into three progenitor populations: (1) $F c \gamma R^{\text {low }}$ CD $34^{+}$cells (common-myeloid progenitors; CMPs) which are capable of generating all types of myeloid lineage, (2) $\mathrm{FC} \gamma \mathrm{R}^{\text {high }} \mathrm{CD} 34^{+}$cells (granulocyte/macrophage progenitors; GMPs), which generate the granulocyte and macrophage lineages, and (3) the $\mathrm{Fc} \gamma \mathrm{R}^{\mathrm{low}} \mathrm{CD} 34^{-}$cells (megakaryocyte/ erythroid progenitors; MEPs), that generate the megakaryocytic and erythroid lineages. The progenitor of the GMP and the MEP is the CMP population [72]. When Sox17-transduced IAHCs are transplanted into irradiated mice, the absolute number of Sox17-transduced-CMPs (Sox17-CMPs) aberrantly increased to a greater extent than that of Sox17-transduced-GMPs (Sox17-GMPs) and Sox17-transduced-MEPs (Sox17-MEPs; see the "transplantation" part of Fig. 2A) [73]. Three populations of progenitors are observed in an in vitro culture system in which Sox17-transduced cells are co-cultured with OP9 stromal cells and Sox17-CMPs are maintained at least after five passages [73]. These results indicate that sustained expression of Sox17 in HSPCs and cells from IAHCs provokes the leukemia-like abnormalities, and the recipient mice finally die.

As mentioned above, ectopic expression of Sox17 in adult HSPCs maintains the long-term repopulating ability with less lymphocytic repopulation capacity and induces the expression of markers associated with fetal HSPCs, for example, CD34 and VE-cad which are markers of endothelial cells, Mac-1 and AA4.1 which are markers of linages in blood cells and fetal HSCs [15]. These maker proteins induced by the Sox17 induction are not expressed in the adult HSPCs. This raises the possibility of a reprogramming from the adult HSCs to fetal HSCs in Sox17-transduced adult HSPCs [74]. Moreover, conditional deletion of Sox17 in the neonate shows a significantly decreased number of HSPCs with increased S/ G2/M proportions [15]. The result opens up the possibility of regulating the cell cycle system by Sox17. Furthermore, Sox17 directly induces the gene expression of Runx1 and Gata2, which are essential transcription factors, and Notch1, which is important for the maintenance of the stem cell phenotype [57].

\section{CONCLUDING REMARKS AND PERSPECTIVES}

In this review, we highlight the expression level of the transcription factor Sox17 in cancer cells in conjunction with the DNA methylation status of the Sox17 gene promoter, and the function of Sox17 in the hematopoiesis in midgestation mouse embryos.

In various cancer cells mainly derived from endodermal tissues, the expression level of Sox 17 is often found to be decreased. This decrease in the Sox17 expression is caused 
by the DNA methylation in the CpG sites of the Sox17 promoter. Moreover, cancer cells with the decreased expression of Sox17 show more malignant characteristics. Furthermore, decreased expression of Sox17 significantly correlates with shorter relapse-free survival in breast cancer and melanoma patients. These results raise the possibility that Sox 17 functions as a tumor suppressor. Future studies on the Sox17 expression level, the methylation status of the Sox17 promoter, and the Sox17 mutations in cancer patients are needed to investigate its relationship to its malignancy. Sox17, through its transcriptional activation domain, directly interacts with $\beta$-catenin and thereby inhibits the $\beta$-catenin-dependent gene transcription in the Wnt signaling pathway. Factors that induce the methylation and the demethylation of the Sox 17 promoter have not been clarified.

Sox17 has a role in the maintenance of the cluster formation with the hematopoietic capability in IAHCs of the dorsal aorta. The molecular mechanism for maintaining the clusters and the undifferentiated state by Sox 17 is the induction of the Notch1-gene expression to keep the hematopoietic activity and the adherent molecule-gene expression to form the cluster. In the dorsal aorta, the expression level of Sox17 is high in endothelial cells, middle in IAHCs, and null in differentiated hematopoietic cells. Contrary to the situation in the most cancers with low Sox17 expression, the regulatory mechanism of a Sox17 expression in the dorsal aorta has not been clearly elucidated. It remains unknown whether decreased expression of Sox17 in IAHCs and no expression of Sox17 in differentiated hematopoietic cells in the dorsal aorta are caused by the methylation of the Sox17 promoter region. Analyses of mice deficient for Notch1 [75] or adherent molecules VE-cad [76] and ESAM [77] show normal hematopoiesis in the dorsal aorta of midgestation embryos. It is necessary to clarify new regulatory molecules by comparing gene expression patterns in Sox17-expressing cells and non-expressing cells.

In some AML patients, the increased methylation level of the Sox17 promoter region leads to a decrease in the Sox 17 expression [69]. The Sox17 expression is increased in cholangiocarcinoma cells with a 5-aza-2'deoxycytidine, which reduces the methylation in CpG sites [24]. Since enforced expression of Sox17 in HSPCs and the cells of IAHCs reveals the leukemia-like abnormalities in the transplanted experiment, simple Sox17 induction strategies may have limitations in being applied to leukemia. Concerning strategies for the treatment of other malignancies involving Sox17 downregulation, if its gene promoter methylation is the major cause, development of drugs that specifically demethylate the Sox 17 promoter would be a promising approach [78-83]. If microRNA-mediated Sox17 downregulation is the major cause, biopharmaceuticals including nucleic acid medicine antagonizing such microRNAs can be applied [84-86]. Further studies will be necessary to validate the therapeutic effectiveness of restoring Sox17 in cancer patients.

\section{ACKNOWLEDGMENTS}

We thank Dr. T. Kagawa and Dr. K. Tabu for valuable discussions. We also thank M. Fushimi and K. Inoue for secretarial assistance. This work was supported by grants from the Ministry of Education, Culture, Sports, Science and Technology of Japan (Grant number 23570250, 26440118 and 18K06249 (I.N.), 22130008, 15H04292, and 18H02678 (T.T.)) and Nanken-Kyoten (Grant number, H26-A39, H27-A35, H28-A11), TMDU, Japan.

\section{CONFLICTS OF INTEREST}

No potential conflicts of interest were disclosed.

\section{ORCID}

Maha Anani, https://orcid.org/0000-0003-4591-1310

Ikuo Nobuhisa, https://orcid.org/0000-0002-3335-7714

Tetsuya Taga, https://orcid.org/0000-0002-1625-0122

\section{REFERENCES}

1. Wilson M, Koopman P. Matching SOX: partner proteins and cofactors of the SOX family of transcriptional regulators. Curr Opin Genet Dev 2002;12:441-6.

2. Bowles J, Schepers G, Koopman P. Phylogeny of the SOX family of developmental transcription factors based on sequence and structural indicators. Dev Biol 2000;227:239-55.

3. Tan DS, Holzner M, Weng M, Srivastava Y, Jauch R. SOX17 in cellular reprogramming and cancer. Semin Cancer Biol 2020;67:65-73.

4. Tam PP, Kanai-Azuma M, Kanai Y. Early endoderm development in vertebrates: lineage differentiation and morphogenetic function. Curr Opin Genet Dev 2003;13:393-400.

5. Liu Y, Asakura M, Inoue H, Nakamura T, Sano M, Niu Z, et al. Sox17 is essential for the specification of cardiac mesoderm in embryonic stem cells. Proc Natl Acad Sci USA 2007;104:385964.

6. Kanai Y, Kanai-Azuma M, Noce T, Saido TC, Shiroishi T, Hayashi $\mathrm{Y}$, et al. Identification of two Sox17 messenger RNA isoforms, with and without the high mobility group box region, and their differential expression in mouse spermatogenesis. J Cell Biol 1996;133:667-81.

7. Saba R, Kitajima K, Rainbow L, Engert S, Uemura M, Ishida $\mathrm{H}$, et al. Endocardium differentiation through Sox17 expression in endocardium precursor cells regulates heart development in mice. Sci Rep 2019;9:11953.

8. Hirate $Y$, Suzuki H, Kawasumi M, Takase HM, Igarashi $H$, Naquet $P$, et al. Mouse Sox17 haploinsufficiency leads to female subfertility due to impaired implantation. Sci Rep 2016;6:24171.

9. Higashiyama $H$, Ozawa $A$, Sumitomo $H$, Uemura M, Fujino $\mathrm{K}$, Igarashi $\mathrm{H}$, et al. Embryonic cholecystitis and defective gallbladder contraction in the Sox17-haploinsufficient mouse 
model of biliary atresia. Development 2017;144:1906-17.

10. Uemura M, Higashi M, Pattarapanawan M, Takami S, Ichikawa $\mathrm{N}$, Higashiyama H, et al. Gallbladder wall abnormality in biliary atresia of mouse Sox $17^{+/}$neonates and human infants. Dis Model Mech 2020;13:dmm042119.

11. Uemura M, Ozawa A, Nagata T, Kurasawa K, Tsunekawa N, Nobuhisa I, et al. Sox17 haploinsufficiency results in perinatal biliary atresia and hepatitis in C57BL/6 background mice. Development 2013;140:639-48.

12. Sohn J, Natale J, Chew LJ, Belachew S, Cheng Y, Aguirre A, et al. Identification of Sox17 as a transcription factor that regulates oligodendrocyte development. J Neurosci 2006;26:9722-35.

13. Chew LJ, Shen W, Ming X, Senatorov VV Jr, Chen HL, Cheng $Y$, et al. SRY-box containing gene 17 regulates the $\mathrm{Wnt} / \beta$-catenin signaling pathway in oligodendrocyte progenitor cells. J Neurosci 2011;31:13921-35.

14. Kim I, Saunders TL, Morrison SJ. Sox17 dependence distinguishes the transcriptional regulation of fetal from adult hematopoietic stem cells. Cell 2007;130:470-83.

15. He S, Kim I, Lim MS, Morrison SJ. Sox17 expression confers self-renewal potential and fetal stem cell characteristics upon adult hematopoietic progenitors. Genes Dev 2011;25:1613-27.

16. Higashijima $Y$, Kanki Y. Molecular mechanistic insights: the emerging role of SOXF transcription factors in tumorigenesis and development. Semin Cancer Biol 2020;67:39-48.

17. de Jong J, Stoop H, Gillis AJ, van Gurp RJ, van de Geijn GJ, Boer Md, et al. Differential expression of SOX17 and SOX2 in germ cells and stem cells has biological and clinical implications. J Pathol 2008;215:21-30.

18. Jostes SV, Fellermeyer M, Arévalo L, Merges GE, Kristiansen G, Nettersheim D, et al. Unique and redundant roles of SOX2 and SOX17 in regulating the germ cell tumor fate. Int $\mathrm{J}$ Cancer 2020;146:1592-605.

19. Matsui T, Kanai-Azuma M, Hara K, Matoba S, Hiramatsu R, Kawakami H, et al. Redundant roles of Sox17 and Sox18 in postnatal angiogenesis in mice. J Cell Sci 2006;119:3513-26.

20. Sakamoto Y, Hara K, Kanai-Azuma M, Matsui T, Miura Y, Tsunekawa N, et al. Redundant roles of Sox17 and Sox18 in early cardiovascular development of mouse embryos. Biochem Biophys Res Commun 2007;360:539-44.

21. Yang H, Lee S, Lee S, Kim K, Yang Y, Kim JH, et al. Sox17 promotes tumor angiogenesis and destabilizes tumor vessels in mice. J Clin Invest 2013;123:418-31.

22. Jia Y, Yang Y, Liu S, Herman JG, Lu F, Guo M. SOX17 antagonizes WNT/ $\beta$-catenin signaling pathway in hepatocellular carcinoma. Epigenetics 2010;5:743-9.

23. Fu DY, Wang ZM, Li-Chen, Wang BL, Shen ZZ, Huang W, et al. Sox 17 , the canonical Wnt antagonist, is epigenetically inactivated by promoter methylation in human breast cancer. Breast Cancer Res Treat 2010;119:601-12.

24. Goeppert B, Konermann C, Schmidt CR, Bogatyrova O, Geiselhart L, Ernst C, et al. Global alterations of DNA methylation in cholangiocarcinoma target the Wnt signaling pathway. Hepatology 2014;59:544-54.
25. Zhang W, Glöckner SC, Guo M, Machida EO, Wang DH, Easwaran $\mathrm{H}$, et al. Epigenetic inactivation of the canonical Wnt antagonist SRY-box containing gene 17 in colorectal cancer. Cancer Res 2008;68:2764-72.

26. Ye YW, Wu JH, Wang CM, Zhou Y, Du CY, Zheng BQ, et al. Sox17 regulates proliferation and cell cycle during gastric cancer progression. Cancer Lett 2011;307:124-31.

27. Kuo IY, Wu CC, Chang JM, Huang YL, Lin CH, Yan JJ, et al. Low SOX17 expression is a prognostic factor and drives transcriptional dysregulation and esophageal cancer progression. Int J Cancer 2014;135:563-73.

28. Zhang Y, Bao W, Wang K, Lu W, Wang H, Tong H, et al. SOX17 is a tumor suppressor in endometrial cancer. Oncotarget 2016;7:76036-46.

29. Yin D, Jia Y, Yu Y, Brock MV, Herman JG, Han C, et al. SOX17 methylation inhibits its antagonism of Wnt signaling pathway in lung cancer. Discov Med 2012;14:33-40.

30. Li JY, Han C, Zheng LL, Guo MZ. Epigenetic regulation of Wnt signaling pathway gene SRY-related HMG-box 17 in papillary thyroid carcinoma. Chin Med J 2012;125:3526-31.

31. Chimonidou M, Strati A, Malamos N, Georgoulias V, Lianidou ES. SOX17 promoter methylation in circulating tumor cells and matched cell-free DNA isolated from plasma of patients with breast cancer. Clin Chem 2013;59:270-9.

32. Balgkouranidou I, Karayiannakis A, Matthaios D, Bolanaki $H$, Tripsianis G, Tentes AA, et al. Assessment of SOX17 DNA methylation in cell free DNA from patients with operable gastric cancer. Association with prognostic variables and survival. Clin Chem Lab Med 2013;51:1505-10.

33. Hansel A, Steinbach D, Greinke C, Schmitz M, Eiselt J, Scheungraber $\mathrm{C}$, et al. A promising DNA methylation signature for the triage of high-risk human papillomavirus DNA-positive women. PLoS One 2014;9:e91905.

34. Mastoraki S, Chimonidou M, Dimitrakopoulos L, Kounelis S, Malamos N, Georgoulias V, et al. A rapid and accurate closedtube Methylation-Sensitive High Resolution Melting Analysis assay for the semi-quantitative determination of SOX17 promoter methylation in clinical samples. Clin Chim Acta 2015;444:303-9.

35. Silva AL, Dawson SN, Arends MJ, Guttula K, Hall N, Cameron EA, et al. Boosting Wnt activity during colorectal cancer progression through selective hypermethylation of Wnt signaling antagonists. BMC Cancer 2014;14:891.

36. Fu DY, Tan HS, Wei JL, Zhu CR, Jiang JX, Zhu YX, et al. Decreased expression of SOX17 is associated with tumor progression and poor prognosis in breast cancer. Tumour Biol 2015;36:8025-34.

37. Lu J, Zhang G, Cheng Y, Tang Y, Dong Z, McElwee KJ, et al. Reduced expression of SRY-box containing gene 17 correlates with an unfavorable melanoma patient survival. Oncol Rep 2014;32:2571-9.

38. Jia Y, Yang Y, Zhan Q, Brock MV, Zheng X, Yu Y, et al. Inhibition of SOX17 by microRNA 141 and methylation activates the WNT signaling pathway in esophageal cancer. J Mol Diagn 2012;14:577-85. 
39. Balgkouranidou I, Chimonidou M, Milaki G, Tsaroucha E, Kakolyris S, Georgoulias V, et al. SOX17 promoter methylation in plasma circulating tumor DNA of patients with non-small cell lung cancer. Clin Chem Lab Med 2016;54:1385-93.

40. Nusse R, Clevers $H$. Wnt/ $\beta$-catenin signaling, disease, and emerging therapeutic modalities. Cell 2017;169:985-99.

41. Sinner D, Rankin S, Lee M, Zorn AM. Sox17 and beta-catenin cooperate to regulate the transcription of endodermal genes. Development 2004;131:3069-80.

42. Alonso-Martin S, Auradé F, Mademtzoglou D, Rochat A, Zammit PS, Relaix F. SOXF factors regulate murine satellite cell selfrenewal and function through inhibition of $\beta$-catenin activity. Elife 2018;7:e26039.

43. Sinner D, Kordich JJ, Spence JR, Opoka R, Rankin S, Lin SC, et al. Sox17 and Sox4 differentially regulate beta-catenin/T-cell factor activity and proliferation of colon carcinoma cells. Mol Cell Biol 2007;27:7802-15.

44. Merino-Azpitarte M, Lozano E, Perugorria MJ, EsparzaBaquer A, Erice O, Santos-Laso Á, et al. SOX17 regulates cholangiocyte differentiation and acts as a tumor suppressor in cholangiocarcinoma. J Hepatol 2017;67:72-83.

45. Li L, Yang WT, Zheng PS, Liu XF. SOX17 restrains proliferation and tumor formation by down-regulating activity of the Wnt/ $\beta$-catenin signaling pathway via trans-suppressing $\beta$-catenin in cervical cancer. Cell Death Dis 2018;9:741.

46. Walker CJ, O'Hern MJ, Serna VA, Kurita T, Miranda MA, Sapp $\mathrm{CE}$, et al. Novel SOX17 frameshift mutations in endometrial cancer are functionally distinct from recurrent missense mutations. Oncotarget 2017;8:68758-68.

47. Nettersheim D, Westernströer B, Haas N, Leinhaas A, Brüstle $\mathrm{O}$, Schlatt $\mathrm{S}$, et al. Establishment of a versatile seminoma model indicates cellular plasticity of germ cell tumor cells. Genes Chromosomes Cancer 2012;51:717-26.

48. Whipple CA, Young AL, Korc M. A KrasG12D-driven genetic mouse model of pancreatic cancer requires glypican-1 for efficient proliferation and angiogenesis. Oncogene 2012;31:2535-44.

49. Kuo IY, Huang YL, Lin CY, Lin CH, Chang WL, Lai WW, et al. SOX17 overexpression sensitizes chemoradiation response in esophageal cancer by transcriptional down-regulation of DNA repair and damage response genes. J Biomed Sci 2019;26:20.

50. Wang C, Li Q, He Y. MicroRNA-21-5p promotes epithelial to mesenchymal transition by targeting SRY-box 17 in endometrial cancer. Oncol Rep 2020;43:1897-905.

51. Yang F, Xiao Z, Zhang S. Knockdown of miR-194-5p inhibits cell proliferation, migration and invasion in breast cancer by regulating the Wnt/ $\beta$-catenin signaling pathway. Int $\mathrm{J}$ Mol Med 2018;42:3355-63.

52. Li Y, Lv Z, He G, Wang J, Zhang X, Lu G, et al. The SOX17/ miR-371-5p/SOX2 axis inhibits EMT, stem cell properties and metastasis in colorectal cancer. Oncotarget 2015;6:9099-112.

53. Medvinsky A, Rybtsov S, Taoudi S. Embryonic origin of the adult hematopoietic system: advances and questions. Development 2011;138:1017-31.
54. Kauts ML, Vink CS, Dzierzak E. Hematopoietic (stem) cell development - how divergent are the roads taken? FEBS Lett 2016;590:3975-86.

55. Boisset JC, Clapes T, Klaus A, Papazian N, Onderwater J, Mommaas-Kienhuis $\mathrm{M}$, et al. Progressive maturation toward hematopoietic stem cells in the mouse embryo aorta. Blood 2015;125:465-9.

56. Yokomizo T, Dzierzak E. Three-dimensional cartography of hematopoietic clusters in the vasculature of whole mouse embryos. Development 2010;137:3651-61.

57. Lizama CO, Hawkins JS, Schmitt CE, Bos FL, Zape JP, Cautivo KM, et al. Repression of arterial genes in hemogenic endothelium is sufficient for haematopoietic fate acquisition. Nat Commun 2015;6:7739.

58. Nobuhisa I, Osawa M, Uemura M, Kishikawa Y, Anani M, Harada $\mathrm{K}$, et al. Sox17-mediated maintenance of fetal intra-aortic hematopoietic cell clusters. Mol Cell Biol 2014;34:1976-90.

59. Saito K, Nobuhisa I, Harada K, Takahashi S, Anani M, Lickert H, et al. Maintenance of hematopoietic stem and progenitor cells in fetal intra-aortic hematopoietic clusters by the Sox17-Notch1Hes1 axis. Exp Cell Res 2018;365:145-55.

60. Taoudi S, Morrison AM, Inoue H, Gribi R, Ure J, Medvinsky A. Progressive divergence of definitive haematopoietic stem cells from the endothelial compartment does not depend on contact with the foetal liver. Development 2005;132:4179-91.

61. Nobuhisa I, Yamasaki S, Ramadan A, Taga T. CD45(low) c-Kit(high) cells have hematopoietic properties in the mouse aorta-gonad-mesonephros region. Exp Cell Res 2012;318:70515.

62. Harada K, Nobuhisa I, Anani M, Saito K, Taga T. Thrombopoietin contributes to the formation and the maintenance of hematopoietic progenitor-containing cell clusters in the aortagonad-mesonephros region. Cytokine 2017;95:35-42.

63. Clarke RL, Yzaguirre AD, Yashiro-Ohtani Y, Bondue A, Blanpain C, Pear WS, et al. The expression of Sox17 identifies and regulates haemogenic endothelium. Nat Cell Biol 2013;15:50210.

64. Robert-Moreno A, Guiu J, Ruiz-Herguido C, López ME, InglésEsteve J, Riera L, et al. Impaired embryonic haematopoiesis yet normal arterial development in the absence of the Notch ligand Jagged1. EMBO J 2008;27:1886-95.

65. Takahashi S, Nobuhisa I, Saito K, Gerel M, Itabashi A, Harada $\mathrm{K}$, et al. Sox17-mediated expression of adherent molecules is required for the maintenance of undifferentiated hematopoietic cluster formation in midgestation mouse embryos. Differentiation 2020;115:53-61.

66. Luis TC, Naber BA, Roozen PP, Brugman MH, de Haas $E F$, Ghazvini $M$, et al. Canonical wnt signaling regulates hematopoiesis in a dosage-dependent fashion. Cell Stem Cell 2011;9:345-56.

67. Koch U, Wilson A, Cobas M, Kemler R, Macdonald HR, Radtke F. Simultaneous loss of beta- and gamma-catenin does not perturb hematopoiesis or lymphopoiesis. Blood 2008;111:160-4.

68. Luis TC, Weerkamp F, Naber BA, Baert MR, de Haas EF, Nikolic 
T, et al. Wnt3a deficiency irreversibly impairs hematopoietic stem cell self-renewal and leads to defects in progenitor cell differentiation. Blood 2009;113:546-54.

69. Ruiz-Herguido C, Guiu J, D’Altri T, Inglés-Esteve J, Dzierzak E, Espinosa L, et al. Hematopoietic stem cell development requires transient Wnt/ $\beta$-catenin activity. J Exp Med 2012;209:1457-68.

70. Griffiths EA, Gore SD, Hooker C, McDevitt MA, Karp JE, Smith $\mathrm{BD}$, et al. Acute myeloid leukemia is characterized by Wnt pathway inhibitor promoter hypermethylation. Leuk Lymphoma 2010;51:1711-9.

71. Tang CY, Lin J, Qian W, Yang J, Ma JC, Deng ZQ, et al. Low SOX17 expression: prognostic significance in de novo acute myeloid leukemia with normal cytogenetics. Clin Chem Lab Med 2014;52:1843-50.

72. Akashi K, Traver D, Miyamoto T, Weissman IL. A clonogenic common myeloid progenitor that gives rise to all myeloid lineages. Nature 2000;404:193-7.

73. Anani M, Nobuhisa I, Osawa M, Iwama A, Harada K, Saito $\mathrm{K}$, et al. Sox17 as a candidate regulator of myeloid restricted differentiation potential. Dev Growth Differ 2014;56:469-79.

74. Chhabra A, Mikkola HK. Return to youth with Sox17. Genes Dev 2011;25:1557-62

75. Tang Y, Bai H, Urs S, Wang Z, Liaw L. Notch1 activation in embryonic VE-cadherin populations selectively blocks hematopoietic stem cell generation and fetal liver hematopoiesis. Transgenic Res 2013;22:403-10.

76. Anderson H, Patch TC, Reddy PN, Hagedorn EJ, Kim PG, Soltis $\mathrm{KA}$, et al. Hematopoietic stem cells develop in the absence of endothelial cadherin 5 expression. Blood 2015;126:2811-20.

77. Ishida T, Kundu RK, Yang E, Hirata K, Ho YD, Quertermous T. Targeted disruption of endothelial cell-selective adhesion molecule inhibits angiogenic processes in vitro and in vivo. J Biol Chem 2003;278:34598-604.

78. Xu X, Tao Y, Gao X, Zhang L, Li X, Zou W, et al. A CRISPR- based approach for targeted DNA demethylation. Cell Discov 2016;2:16009.

79. Gallego-Bartolomé J, Gardiner J, Liu W, Papikian A, Ghoshal B, Kuo HY, et al. Targeted DNA demethylation of the Arabidopsis genome using the human TET1 catalytic domain. Proc Natl Acad Sci USA 2018;115:E2125-34.

80. Hanzawa N, Hashimoto K, Yuan X, Kawahori K, Tsujimoto K, Hamaguchi M, et al. Targeted DNA demethylation of the Fgf21 promoter by CRISPR/dCas9-mediated epigenome editing. Sci Rep 2020;10:5181.

81. Morita S, Noguchi H, Horii T, Nakabayashi K, Kimura M, Okamura $\mathrm{K}$, et al. Targeted DNA demethylation in vivo using dCas9-peptide repeat and ScFv-TET1 catalytic domain fusions. Nat Biotechnol 2016;34:1060-5.

82. Parrilla-Doblas JT, Ariza RR, Roldán-Arjona T. Targeted DNA demethylation in human cells by fusion of a plant 5-methylcytosine DNA glycosylase to a sequence-specific DNA binding domain. Epigenetics 2017;12:296-303.

83. Maeder ML, Angstman JF, Richardson ME, Linder SJ, Cascio VM, Tsai SQ, et al. Targeted DNA demethylation and activation of endogenous genes using programmable TALE-TET1 fusion proteins. Nat Biotechnol 2013;31:1137-42.

84. Velagapudi SP, Gallo SM, Disney MD. Sequence-based design of bioactive small molecules that target precursor microRNAs. Nat Chem Biol 2014;10:291-7.

85. Costales MG, Aikawa H, Li Y, Childs-Disney JL, Abegg D, Hoch DG, et al. Small-molecule targeted recruitment of a nuclease to cleave an oncogenic RNA in a mouse model of metastatic cancer. Proc Natl Acad Sci USA 2020;117:2406-11.

86. Patutina OA, Bazhenov MA, Miroshnichenko SK, Mironova NL, Pyshnyi DV, Vlassov VV, et al. Peptide-oligonucleotide conjugates exhibiting pyrimidine-X cleavage specificity efficiently silence miRNA target acting synergistically with RNase $\mathrm{H}$. Sci Rep 2018;8:14990. 